
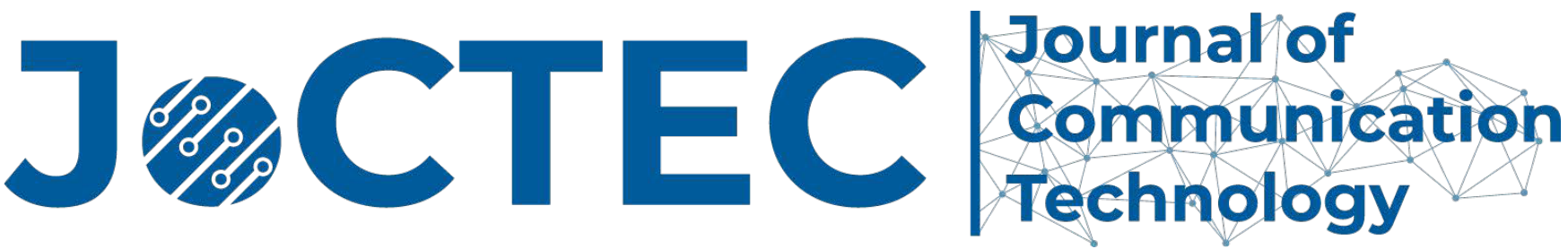

Published by the Communication Technology Division

of the Association for Education in Journalism and Mass Communication

Peer review: This article has been subject to a double-blind peer review process

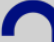 \\ (2)}

open access

JoCTEC is an open access journal meaning that all content is freely available without charge to the user or their institution. Users are allowed to read, download, copy, distribute, print, search, or link to the full texts of the articles, or use them for any other lawful purpose, without asking prior permission from the publisher or the author.

Open access is an ongoing publication practice that differs from the traditional manner academic journals are published and then received by the reading public. In Open Access publication model neither readers nor a reader's institution are charged for access to articles or other resources. We ask that users in turn give proper citation of the original publication or link to the full texts of these articles for any non-commercial purposes A subscription to the journal in which these articles are published is not required.

\title{
Growing Up on Facebook [Book Review]
}

\section{Corey Jay Liberman}

Marymount Manhattan College, New York City, New York, USA

Correspondence: cliberman@mmm.edu

Growing Up on Facebook, authored by Brady Robards and Sian Lincoln, exposes the reader to the role of Computer-Mediated Communication in creating, recreating, and altering the online identities of users. Highlighting the role of self in intimate relationships, professional relationships, and family relationships, Robards and Lincoln discuss such identity markers as friend requests, postings of photos, political discourse, and the creation of profiles, providing the fields of communication, sociology, and social psychology with an overview of the antecedents, processes, and effects of the social construction of self on Facebook.

The authors include data from their Facebook Timelines empirical study, which qualitatively analyzed the role that Facebook played in the social lives of 41 participants who, per the title of the book, were the first generational cohort to have Facebook saturate their social interactions and relationships. As each new topic within the book is introduced and explored, Robards and Lincoln are able to interject testimonials from their subjects, based on a scroll back method (p. 51), where they asked participants to retroactively recreate their Facebook lives and selves in reverse chronological order (from present to yesteryear). Whether the authors were speaking about the role of Facebook in publicizing intimate relationships (p. 108), circumnavigating the boundaries between professional and nonprofessional online selves (p. 93), or the production of digital traces ( $p$. 152) about which Robards and Lincoln speak say volumes about the use of Facebook as a mediated platform for the production of identity.

Robards and Lincoln also effectively introduce the scholarly literature focusing on identity, with perpetual mention of both Erving Goffman 
and Anthony Giddens. As they introduce each new idea and argument, the reader is always reminded of the link back to, for example, Goffman's dramaturgical framework of the self (p. 41) and Giddens' reflexive project of the self (p. 103), both of which inform, and are informed by, how the participants highlighted throughout the text saw and used Facebook as a platform for the performance of self and identity. It should be noted that while the reader need not to have been exposed to the scholarship of these prolific scholars to understand the key theses offered within Growing Up on Facebook, a basic understanding of their approaches to communication and the social construction of identity would provide a richer reader experience. Considering the strategic ways that Robards and Lincoln situate and explain such variables as backstage work (p. 6), identity regions (p. 35), reflexive self-making (p. 45), the stable individual ( $p$. 82 ), audience segregation (p. 90), and the pure relationship (p. 106), this could leave readers lacking.

Early in the first chapter, the authors introduce the idea that Facebook has provided both challenges and opportunities for the creation and development of interpersonal relationships and, concomitantly, for the construction (and co-construction) of identities. In the chapter that follows, they speak about the probability of a context collapse (p. 16), wherein users need to be much more wary, as Goffman argues in his own research, of the self that they are manifesting (friend self, employee self, lover self, familial self) to determine whether and to what extent these remain private or become more public. Robards and Lincoln, again, as they do throughout their entire text, link this idea back to the non-mediated scholarship, and how social actors have forever been doing this type of identity work. Chapter three focuses much on the idea of digital dualism (p. 28) and how, according to the authors, rather than there being a discernable partition between the digital and the physical (the mediated and the real), Facebook provides an interesting "blurring" of the two (p. 29). Using Goffman's theatrical metaphor of the coconstruction of identity, the reader learns that this blurring occurs as a result of the deconstruction and decoding of one's own, and one's relational partner's, performative self.

Chapter four then introduces the reader to the scroll-back method employed by Robards and Lincoln, during which they explained that their choice to study participants "in their twenties" (p. 51) was because these are members of the first cohort of individuals to, as the title of the book implies, grow up on Facebook. The reader is reminded that the goal of the text, and of the authors' study, is to showcase how Facebook provides a digital landscape for the construction of identity and for the "re-piecing together" (p. 62) of 
social life. The chapter stresses the idea of the narratives that are produced by Facebook users and which are stored on the social media platform itself. As the 41 participants began to "grow up," their mediated narratives began to change: analogous with how identities change and [likely] mature as a result of the aging process. Articulately combining these two ideas, Robards and Lincoln claim that their project provides ".... long-term narrative that captures the nuances of growing up over an extended period of time" (p. 69).

The next four chapters describe the results of the Facebook Timelines study, focusing on four major dependent variables shaped by the online platform. In the fifth chapter, Robards and Lincoln speak about the changing nature of self as participants entered the workforce and how they felt the need and desire, through the selfreflection practices mentioned throughout the text, to edit their online identities to conform more closely with the expectations of potential employers. Based on a multitude of participant testimonials, Robards and Lincoln make it clear that participants had a desire to engage in "identity work" (p. 92) as they were both entering the workforce and also becoming a part of it. Chapter six focuses on the role of Facebook as a conduit for the social construction and storytelling of intimate relationships and love: what Robards and Lincoln argue are now, due to social media platforms, purposefully publicized processes. Highlighting the results from their Facebook Timelines project, the authors showcase the multitude of "relationship narratives" (p. 104) that manifested, and how such relational markers as relationship status (p. 103), going Facebook Official (p. 107) and de-friending (p. 114) come to produce constructed, and coconstructed, identities.

Chapter seven discusses the role of Facebook in providing a social conduit through which familial connections can be maintained and strengthened. From getting the initial approval by parents to become part of the Facebook world (p. 131) to family members filtering what could and could not be posted (p. 134), it becomes clear, as Robards and Lincoln claim, that "In a number of instances, critical moments were identified as those related to family life and key family events" (p. 129). Chapter eight considers the performance of the leisure self and how this comes to shape both identities and the relationships between and among social actors. In detailing examples of participants' nights out (p. 150), photos from recent travel expenditures (p. 156), or the mediated communication of a love for, and appreciation of, music (p. 162), Robards and Lincoln argue the need for an authentic presentation of self, “...being able to 'see you're having a good time' is important, and, moreover, being able to see this on social media makes people more authentic, likable, 
'well- rounded,' and seem sociable" (p. 154). The authors state, "In this respect, having a totally sterile profile where there appears to be no evidence of 'having a good time' might be considered almost as dubious as having one that is full of drunken nights out. The sterile profile is flagged as suspicious" (p. 154). In other words, it is as important via Facebook, as it is in our non-mediated lives, to create an authentic sense of self.

The book concludes by suggesting how Facebook might not always be the platform conducive for the social construction of one's authentic self because certain "...periods of transition... never made it to Facebook, or...would never have been appropriate for Facebook: experiences of depression, loss, even periods of intense work" (pp. 170-171). Thus, while the Facebook Timelines project provides the academic and social worlds with a rich data set about the longitudinal social practices of users, there are purposeful gaps that produce some whitespace in the digitized lives of said participants.

Overall, Growing Up on Facebook contained extensive participant testimonies and includes scholarship from communication and sociology literatures, which provided a great fusion of theory and practice. The Facebook Timelines project, in and of itself, was an astute way of showcasing the progression and projection of self via a mediated platform, highlighting the risks, rewards, opportunities, and challenges associated with the online presentation of self. Of interest is Brady and Lincoln's claim that "while we can appreciate that social media opens up a range of possibilities for individuals to explore aspects of their identity...its uses also conform to and perpetuate existing hegemonic structures" (p. 43). Thus, the reader is left wondering whether Facebook is an extension of the nonmediated identity world or an outright replacement of it. Among the glories of Growing Up on Facebook is that while there will not be just one, objective answer to this query, the reader, based on the arguments and examples provided by Robards and Lincoln, will be well-positioned to provide an answer. 
Corey Jay Liberman (Ph.D., Rutgers University, 2008) is an Associate Professor of Public Relations and Strategic Communication in the Department of Communication and Media Arts at Marymount Manhattan College. His research spans the interpersonal communication, group communication, and organizational communication worlds, and he is currently interested in studying the social practices of dissent within organizations, specifically the antecedents, processes, and effects associated with effective employee dissent communication, as well as risk and crisis communication. He is currently working on a co-edited book entitled Casing Nonverbal Communication and a co-authored book entitled Organizational Communication: Strategies for Success ( $3^{\text {rd }}$ Edition). He is coauthor of Organizational Communication: Strategies for Success ( $2^{\text {nd }}$ Edition) and Risk and Crisis Communication: Communicating in a Disruptive Age, editor of Casing Persuasive Communication, and co-editor of Casing Crisis and Risk Communication, Casing Communication Theory, and Casing Mediated Communication: all published by Kendall Hunt.

\section{References}

Robards, B., and Lincoln, S. (2020). Growing Up on Facebook. New York: Peter Lang.

To cite this article:

Liberman, C.J. (2021). Growing up on Facebook [Book Review]. Journal of Communication Technology, 4(1), 101-105. DOI: 10.51548/joctec-2021-006. 